\title{
Pedagogy and Social Critique in the Era of Fragmentation: A Collective Writing Experiment as cadavres exquis
}

Visual Knowledge Creation and Critique

Veronica Garcia Lazo ～O ORCID: 0000-0003-1342-7540

Assistant Professor, Pontificia Universidad Católica de Chile, Santiago, Chile veronica.garcia@uc.cl

Kirsten Locke | ORCID: 0000-0002-2089-2793

Senior Lecturer, School of Critical Studies in Education, University of Auckland, Auckland, New Zealand

k.locke@auckland.ac.nz

\section{Nicolas Rupcich}

Independent Visual Artist from Chile, Leipzig, Germany

nicolasrupcich@gmail.com

Gabby O'Connor | ORCID: 0000-0001-7130-1511

University of Auckland, Auckland, New Zealand

The National Institute of Water and Atmospheric Research (NIWA),

Auckland, New Zealand

goco441@aucklanduni.ac.nz

\section{Caroline Yoon}

The University of Auckland, Auckland, New Zealand

c.yoon@auckland.ac.nz

Alys Longley | ORCID: 0000-0002-7687-6290

The University of Auckland, Auckland, New Zealand

a.longley@auckland.ac.nz 


\begin{abstract}
This is the result of a collaborative and creative experiment, a process in which six scholars-Garcia Lazo, Locke, Rupcich, O'Connor, Yoon and Longley—agreed to co-author an article through written and/or visual pieces of work. The emphasis taken in the article is to perform a methodology of fragmentation. The article is to be read as a series of 'folds', where collages or fragments of text are contained and while each fold is numbered, the reader is invited to read any fold in any order. Using fragmentation as method in writing also inspired our interpretation of a body of work made up of multiple 'folds' from the collaborative parlour game played by the surrealist movement. Known as cadavre exquis, surrealists enjoyed the strange juxtaposition created by each artist's contribution as they drew part of a body onto a folded piece of paper without seeing the previous drawings in each fold. While often referred to in the context of psychoanalysis, we instead emphasise the fragmentation and hybridity of this form of collaboration in order to critique of universalising narratives about education (and writing) that we consider to be at odds with the post-capitalist realities of contemporary education and life.
\end{abstract}

\title{
Keywords
}

visual knowledge creation and critique - fragmentation - fold - education pedagogy - cadavres exquis

\section{Introduction}

The aim of this article is to problematize and embody the notion of fragmentation through an experiment of collaborative writing. Fragmentation is considered a pervasive social phenomenon that emerges as a reaction to totalising narratives and as a consequence of emergent technologies in the context of late capitalism (Lyotard, 1988). Ellison (2019) elucidates fragmentation as a cultural crisis wherein society is fractured by neoliberal discourses, where policies in the context of globalization have worsened already-precarious working conditions, social segregation and uneven power relations. Ellison (2019) argues that fragmentation can be understood as a force with sociological and ontological effects that distort and decontextualize the processes of social formation. In this context, Ellison calls for re-contextualizing the disjointed fragments of society through a holistic and critical analysis. Rather than reaching totalising claims, re-contextualizing a fragmented society is an intellectual endeavour that seeks to problematize fragmentation. In education, this task 
entails making visible the ideological structures that underpin certain policies, curricula design and pedagogical practices by revealing their connections with wider society. It also involves the "willingness to transgress disciplinary, theoretical, and methodological borders" (Ellison, 2019, p. 289). In this article, the aim is to embrace a critical and transdisciplinary orientation towards our experiences of fragmentation in the context of a highly technologized world. Consistent with this approach, this article adopts the methodological framework of collage.

Cran (2014) explains that the artistic technique of collage was conceived for its poetic associations and evolved into a plastic process that consists in reappropriating fragments of diverse materials from different sources and assembling these into a new whole. Since its origins in the nineteenth century, the method of collage has been widely adopted for its oppositional potential in questioning art traditions, the political order, mainstream culture, conventional perceptions, and unifying narratives through fragmentation (Cran, 2014). For Etgar (2017), the use of collage as a form of social critique is evident in the oeuvre of early feminist artists from the 1970 s who examined discourses about the female body and women's domestic culture. Feminist writer and art critic Lucy Lippard (1995) conceives that "collage is born of interruption and the healing instinct to use political consciousness as a glue with which to get the pieces into a new order ... though not necessarily as new whole" (p. 168). She considers that collage resonates with feminist and political artists because marginalized groups often experience their subjectivities as unstable, multiple and fluid. From this viewpoint, the power of collage lies in its oppositional and reconstructive force for envisioning multiplicity and alternative forms of identity within a particular dominant culture. While collage emerged to subvert conventions, as well as to critique capitalism and hegemonic values of western society, some theorists conceive collage as simply a symptom of a fragmented commodified culture. Jameson (2002) remains sceptical about the political potential of art and considers practices such as collage, a pastiche, a symptom of postmodern fragmentation derived from late capitalism and commodity culture. In contrast, Dyer (2007) considers pastiche as a divergent way of thinking with strong creative potential since it disrupts the borders between high and low culture by mixing artefacts from both realms. Jameson's (2002) and Dyer's (2007) contrasting considerations enabled the authors to recognise that practices of fragmentation such as collage can simultaneously reflect consumerist rationalities through the appropriation of fragments and forces of resistance that challenge unifying narratives. As Drucker $(2005,2009)$ points out, the perils of contemporary art lie on its engagement with the culture of the market and its oppositional stance towards mainstream discourses. Despite contradictions, current artistic endeavours still have the potential of enacting criticality 
by revealing the rationalities that propel its practices (Drucker, 2009). Awareness about the risks of adopting a methodology based on fragmentation and transparency regarding the intentions that drove us to perform this throughout this article helped us to draw upon the political purchase of collage in critiquing capitalist consumer culture.

In this article, we explore the theorising and pedagogical capacity of collage to question capitalist, hegemonic, patriarchal and colonial forces of power and subjugation through its particularly fragmentary and deconstructive methodology. First, we describe the process that brought six scholars to co-author this article driven by the idea of enacting a radicalizing methodology through the visual. We follow with textual and visual assemblages to analyse the effects of fragmentation on ideas of society and selfhood. We then conclude with a discussion that delves into the possibilities of this methodology in education. The article is to be read as a series of collages where authorial voice at times is blended between the authors, and where text, images, and videos created by them are juxtaposed into the temporal condition of reading and thinking by the reader-viewer. Each section is to be read as a 'fold', where fragments of text are contained and while each fold is numbered, the reader is invited to read any fold in any order. Inspired by Deleuze's reading of Leibniz (1992), the article as a 'whole' is to be interpreted as a 'body' of work that consists of multiple folds and surfaces, where the form 'text' takes, whether it be visual, poetic, or multimedia, is intended as the material expression of the displaced 'voices' of the authors. Using fragmentation as method in writing also inspired our interpretation of a body of work made up of multiple 'folds' from the collaborative parlour game played famously by members of the surrealist movement. Known as cadavre exquis (which means 'exquisite corpse'), surrealists enjoyed the strange juxtaposition and metamorphosis created by each artist's contribution as they drew part of a body onto a folded piece of paper without seeing the previous drawings in each fold. While often referred to in the context of psychoanalysis and the subconscious, we instead emphasise the fragmented and hybrid elements of this form of collaboration so that, we hope, the article 'lands' on a critique of universalising narratives about education (and writing) that we consider to be at odds with the post-capitalist realities of contemporary education.

\section{2 \\ Fold 1: Radicalizing Methodology through the Visual: A Workshop That Sparked Collective Writing}

The idea of engaging in this collaborative work was sparked in response to the workshop Radicalizing methodology through the visual offered by Garcia Lazo 
and Locke at the Association of Visual Pedagogies' 2018 annual conference. The workshop entailed a theoretical presentation and an interactive activity. The theoretic component introduced the principle of fragmentation as both a symptom of late capitalism and a means to critique the socio-economic and political system. Fragmentation was examined as an effect of what Lyotard (1984) refers to as a postmodern condition, a society in a crisis of disbelief triggered by the unfulfilled promise of the modernist project, which assumed that scientific knowledge would lead to social emancipation. Usher and Edwards (1994) argue that this view entailed privileging science over other forms of producing knowledge and the need of imparting this to others by centralizing education. Rather than emancipating society, such a totalising stance excluded difference through consecutive grand narratives that aimed to epistemologically unify the experience of the world. In this scenario of scepticism emerged the logic of capitalism, which rationality replaces emancipatory ideals with principles of efficiency and profit. Instead of a unifying view, society imagines its future as fragmented, because capitalism allows for multiple discourses as long as these support the logic of the market (Lyotard, 1988). Fragmentation appears as a phenomenon with social and pedagogical implications, wherein culture, knowledge and identity, can be turned into commodities. In the context of the workshop, experiences with new visual technologies were examined as part of a postmodern milieu of commodified narratives that are continually constructed with fragments appropriated from diverse sources. The presentation analysed diverse visual experiences in the context of a capitalist-consumer era, the underlying forces that drive certain operations of fragmentation and appropriation in social media, platforms with strong effects on the search of young people's identity.

For the practical module in the workshop, participants were invited to encapsulate their reflections through an individual collage, and to engage in the collective construction of a collage. The point of using the approach of collage during the workshop, was to draw a parallel to the negotiations young people face in their daily lives in which compromised and resistant forces are at play and wherein the impossibility of escaping the capitalist system turns their agentic navigations into fragmented selves. Participants were given glue, scissors, magazines, newspapers, and plain coloured paper as their materials. For the creation of individual collages, participants were invited to reflect on how their daily engagement with the visual affected the construction of their selfnarratives in social media as staged performances. While workshop participants were working on their own collages, they also worked on a collaborative collage. For this collaborative piece, participants were asked to reflect on how visual technologies shape their discourses. Here, the emphasis was on what was removed or altered from their identities. For this work, each participant 
was asked to add an element to the composition of a body and to alter an aspect that had been previously incorporated by another contributor. In discussion with the participants in the workshop as they were making their collages, a sense of criticality emerged from the fragmentary nature of the approaches used, a dimension that to a certain extent mirrored their commoditized engagements in a capitalist and technologized society. These discussions also pointed out the 'static' quality of the activities that participants were asked to engage with, an issue that led Garcia Lazo and Locke to invite them to write an academic article as co-authors of an interactive collage, so that some of its collaborative and fluid performative dimensions could be enacted in the present article. From 15 workshop participants, three-O'Connor, Yoon and Longleyjoined their creative forces with Garcia Lazo and Locke, and became co-authors of this article.

To write this article, co-authors were asked by Garcia Lazo and Locke to reflect upon their experiences of fragmentation in the context of a highly technologized era and reality. The idea was for co-authors to send in their work to Garcia Lazo and Locke, who organised the contributions into the written and visual text of this article. In this article, all images and multimedia were created by the authors. In the timeframe of this process of collaboration, massive social unrest erupted in Chile in response to sustained and severe inequality. Garcia Lazo and Locke considered this uprising to demonstrate an effect of fragmentation understood as a social fracture that is produced and reinforced by the logic of capitalism, which marginalises certain groups. In this context, a myriad of creative manifestations emerged to capture the discontent of the fragmented Chilean society and enact a form of resistance. As a consequence, Rupcich, an artist who uses the idea of fragmentation as a form of social critique was invited to contribute to the article as one of the co-authors. While some written pieces elaborated by the authors are embedded in the article without mentioning their specific authorship, others emerge with a clear voice to open new lines of flight. In this context, this article becomes an apparatus of fragmentation through a collaborative process that aims to examine how this practice simultaneously works as a symptom of consumer capitalism and a means to critique capitalism's artifice. To engage in such cooperative activity, we adopted the practice of collage, a method that emerged as a form of critique of dominant discourses and which has been reinvigorated through new media.

This article, thus, uses multimodal forms of communication including written and visual means, and engages with a fragmentary temporality in terms of its contributions. In this article, fragmentation is also present in the different writing tones of each section, an aspect that reflects the co-authors' field, topic or type of contribution. The article entails theorizations about the idea of 


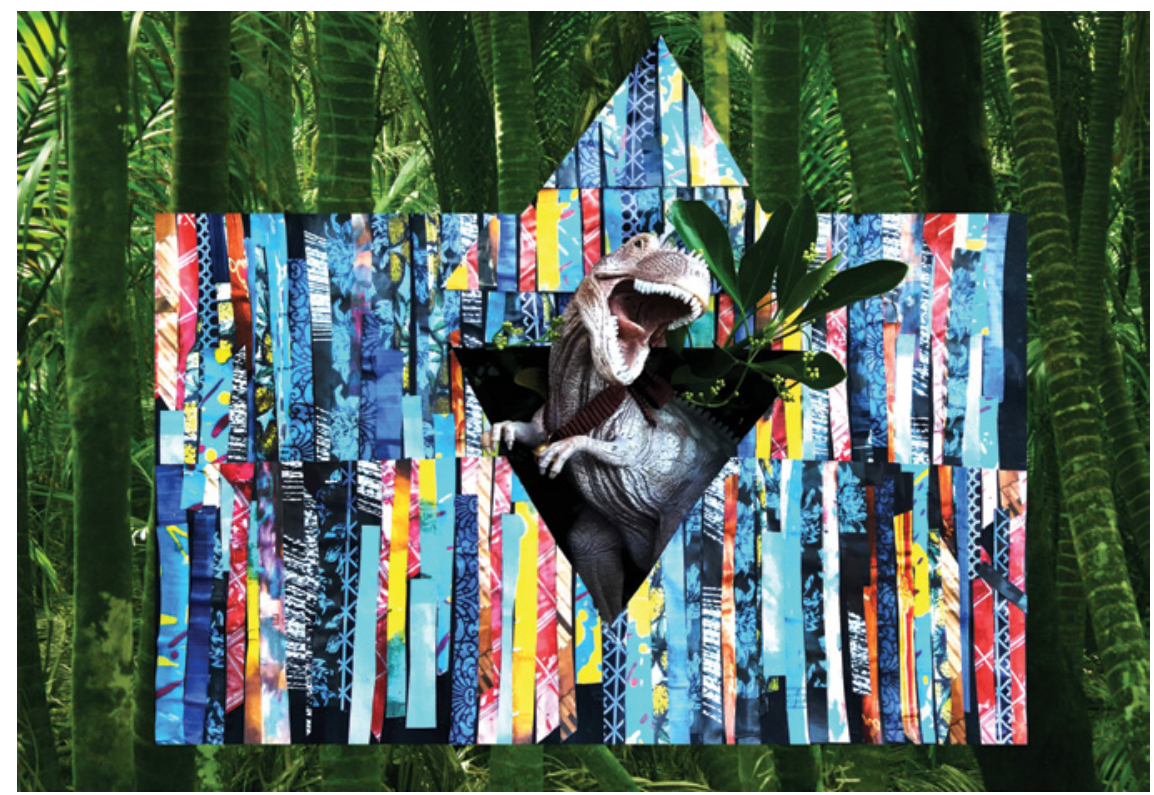

FIGURE 1 The Jurassic World of universities - appropriation and further fragmentation of O'Connor's collage by Garcia Lazo.

fragmentation, visual data generated by the co-authors within the context of the workshop or afterwards and poetry triggered by their reflections after the symposium. It also involves art pieces from artists that are critically engaged in practices of fragmentation and who explore the political potential of its operations to critique the effects of late capitalism. Consistent with the interactive character proposed for the article, some contributions were further appropriated and transformed by other co-authors. Collaborative writing was ultimately thought of as a way of resisting the emphasis on individual outputs currently required from academics in the context of neoliberal discourses that demand high levels of productivity and accountability in order to be competitive in the educational market. The corporatization of universities in late capitalism can be seen as a Jurassic World, which in the name of economic growth has turned education into a park for the amusement of the privileged, a site that has been fractured to strip its power for producing social change. The idea of universities as a Jurassic World is conveyed in Garcia Lazo's appropriation and further fragmentation of author O'Connor's collage (see Figure 1).

In education, Ellison (2019) contends that fragmentation can be understood as a problem with ontological and epistemological effects, a force that disconnects discourses from macro-social issues. This fragmented context calls for 
the enactment of a critical and holistic view in order to question and reveal the connections between different narratives, the students' lived experiences and social reality.

Fold 2: Fragmentation, Politics, and Affect in Education

In the context of education, the ambivalence of the fragmented self and its political potential are both at play. Students are also located within an educational discursive space that is extremely fragmented in terms of policy, curriculum and pedagogy (Garcia Lazo, 2018). As such, the space of education could be seen as a highly complex and fluid assemblage (Deleuze \& Guattari, 1987) of rationalities that locate students and teachers in a symbiotic relationship of interaction and engagement that embodies a mobile positionality that impacts the creation and constitution of multiple 'selves'. In the workshop that informs this article, discussion ensued about the implications this form of identity building had on education broadly conceived, and the ways young people in education are confronted with the need to construct themselves as flexible, fragmented, and continuously adaptable subjects in the context of the shifting demands of the labour market. This emphasis on enacting fluid subjectivities that are able to adjust themselves is echoed in current visual culture and aesthetic experiences which young people produce and are subjected to in their daily lives (jagodzinski, 2010). Heywood and Sandywell (2012) define visual culture as an all-embracing and eclectic notion that entails a wide range of image-making experiences "that mediate the practices and structures of everyday life" (p. 32). The problem with current visual experiences in the context of late capitalism and new technologies, is that these are often engrained within consumer discourses that seek to commodify the self and turn it into a desiring subject (Brown, 2003). As Grushka (2005) maintains, the visual is frequently used to profit and promote certain ideas through the image of youth. As a result, visual experiences can often trigger on young people intense, but ephemeral urges to constantly fit their identity into particular models. For workshop participant and co-author Longley, this continuous desire of the self to be fluid is reflected in social media in the expectation of producing 'likeness', in the form of views, likes and positive comments that respond to personal images posted online. She believes that this pursuit for likes is reflected in the endless assemblages that constitute individuals' self-narratives. Through her poem, Longley alludes to the artifice of self-imageries and contributes to the body of ideas in this article in the following: 
this collage moves through response to colour, texture and the images that correspond to how I sense my body - a certain shape of clouds

the way two shades of green spark a vibration that corresponds to this porous body moving and moved by and forming and reforming - more monstrous than a suburban magazine body, more playful, loose, incongruous, unkempt, vibratory....

Workshop participant and co-author Yoon considers fragmentation in education to have negative effects on minority groups. For her, this is reflected in the way women from non-western cultures are compelled to adapt their identity to a predominantly male-white-gaze view of femininity. Her idea of fragmentation reflects Raaberg's (1998) view of "double-visioned cultural critique", where collage is used to capture a marginal minority perspective. Fifteen minutes into the Radicalizing methodology through the visual workshop, Yoon started feeling uncomfortable. The organisers had provided magazines and newspapers: familiar, popular print media, the kind found in doctors' waiting rooms with pages predominantly filled with white faces and stories - not that this bothered Yoon whenever she flipped through them as an idle way to pass the time. But this was a workshop not a waiting room, and as she assessed the images as potential components of her collage, she started to frown. How could any of them describe how her daily engagement with the visual influenced the construction of her self-narrative?

For Yoon, a second-generation New Zealander whose parents immigrated from Korea in the 1970s, the issue of Asian representation in mainstream 'Western' media was an old, familiar ache. Research in the U. S. shows Asians have traditionally been both underrepresented and misrepresented in film, television, advertisements, and other media, featuring as reductive stereotypes (if at all) with damaging outcomes for Asian American identity development, intergroup interactions, and mental health (Mok, 1998; Besana, Katsiaficas, and Brittian Loyd, 2019). As an Asian New Zealander, Yoon could relate, and as she flipped through pages promoting white beauty, lifestyle, and glamour, she began to wonder whether she would be able to complete her collage at all.

To her surprise, she found in the third magazine a full-page advertisement for some luxury item, featuring an Asian model. But surprise turned into incredulity as she registered that the model's skin had been thickly dusted with white powder, her hair combed through with white paint or cream, and that even her eyelashes had been coated with white mascara. The irony was resounding: The only Asian to be featured in three magazines had been 


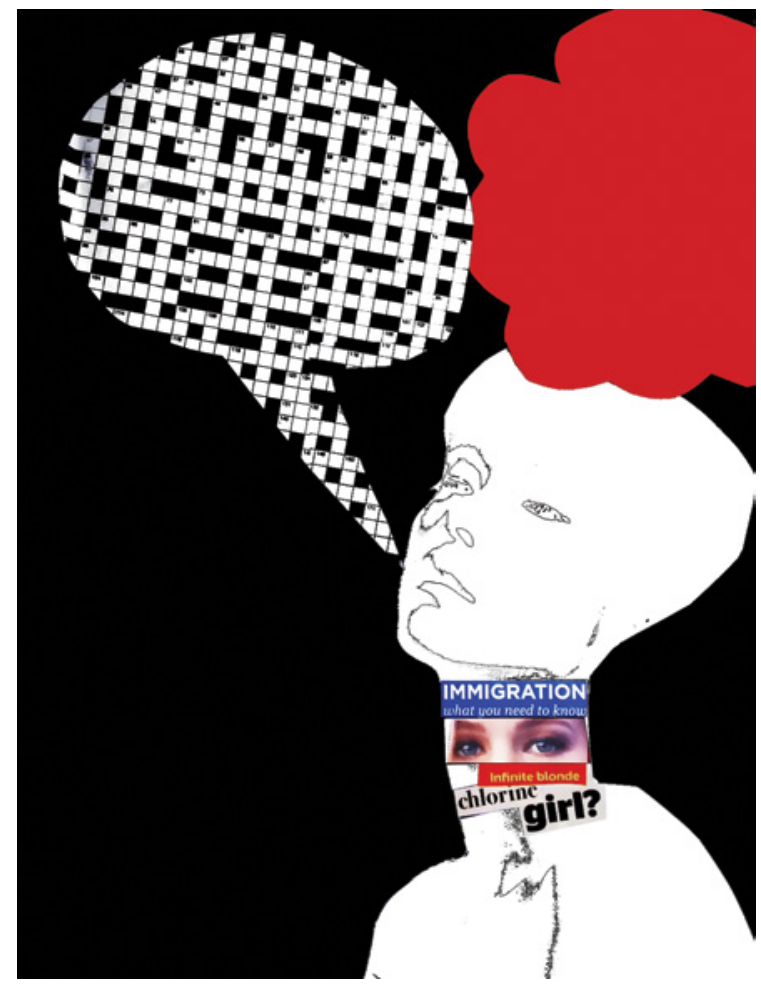

FIGURE 2

Collage by Yoon. Due to copyright issues, the original image of the model has been digitally altered.

whitewashed for no obvious reason. Yoon couldn't have asked for a more fitting response to the organisers' question, and her collage quickly materialised (see Figure 2).

This experience triggered for Yoon another memory of flipping through magazines as a 10-year old child, this time at a university library, where she had discovered a stack of women's fashion magazines that had been imported from Korea. For the first time in her home country of New Zealand, she stared greedily at pages and pages of beautiful, fashionable, confident women who possessed similar racial features to her own. But delight turned into bewilderment when she found several of the pages had been scribbled over in blue pen, with words describing lewd sexual acts the vandal wanted to do to the models. Judging by the vandal's description of his own genitalia, they were the words of a white man that disrupted and distorted Yoon's appreciation of those rare positive Asian images. For Yoon, this memory bore such uncanny parallels to her experience of collaging in the workshop experience that she recorded them in a visual poem afterwards, model minority | minority model: 


\begin{tabular}{r|l} 
model minority & minority model \\
the only face like mine is white & those faces are all like hers \\
white hair dye & $\begin{array}{l}\text { dark tilted eyes } \\
\text { smooth black hair } \\
\text { white powder blended down }\end{array}$ \\
yellow exposed neck & in a confindent pose \\
put a black model in whiteface? & what? someone's already been there \\
yet they approved this & with a ballpoint pen? \\
asians won't mind & hey sexy girls \\
they're so polite & wanna fuck? \\
impressive work ethic but & bet you can't handle this \\
highly conformist & big white cock
\end{tabular}

When taken separately, the text on either side of the dividing line is a poem in itself, recounting Yoon's experiences in the collaging workshop, and in the library. But the text can also be read as a single poem, the lines on each side running on to each other. When read this way, the fragments join in ways that underscore the intersectionality of the two experiences: the totalising authorial power of the editor who approves the whitewashing of the Asian model intersects with that of the vandal who overwrites the pictures of Asian models with his white male gaze.

The term 'model minority' in the title is a further example of this overwriting of Asians into an acceptable white framework. First appearing in popular U. S. newspaper articles during the Civil Rights movement in the 196os, the term ostensibly praises Asians for their educational and income successes, achieved through their formidable work ethic. However, the term has also been described as a fragmenting hegemonic device that pits Asian Americans against other racialised groups by using their achievements to silence and discredit African Americans' rightful charges of racial injustice (Lee, 2009), thereby disrupting potential alliances among people of colour against a common oppressor. The 'model minority' stereotype further fragments Asian Americans themselves into qualities that are deemed acceptable to the dominant group (hard work, compliance) and those that are not. For Asian Americans, and Asian New Zealanders like Yoon, challenging this stereotype means risking their inclusion: is it better to be grateful that they are partly valued than to be rejected altogether? 
Thoughts like these swirled and shrieked through Yoon's head during the workshop as she assembled her collage, but at the time they were raw, confused, not ready to share. In the days that followed, however, she found her thoughts rearranging and reassembling into new insights as she collaged texts to write the model minority $\mid$ minority model poem. When she finalised the join of the last two lines, she laughed at the absurdity of the "highly conformist big white cock". Words that had once been so oppressive on their own became ridiculous when collaged, and she came to see them as more revealing of the insecurities, obsessions, and weaknesses of those who spoke them, than those at whom they were aimed. For Yoon, collage became a form of activism and resistance, defusing the power of harmful stereotypes through humour.

What might we learn from Yoon's experience as educators? It might be easy to suggest that the organisers could have found more diverse and inclusive images for Yoon to identify with, just as teachers are often encouraged to create more inclusive curricula. But the philosopher Sharon Todd warns that "focusing on more inclusive representation for the purposes of identification is not sufficient" for creating the conditions for ethical educational relationships (Todd, 2003, p. 40). Instead, she encourages us to listen, to be open and susceptible to being moved by the unpredictable ways students respond to our provocations (Todd, 2003). This can be seen in the actions of the workshop organisers, who created space for Yoon's unpredictable response, invited her to reflect on and develop it afterwards, and included it as one of the bizarre, untotalisable segments of the cadavre exquis. Importantly, Yoon foreshadows a particular pedagogical response available to artists through a fragmented feminine lens, where identity, race, and sexuality can be diffracted through pastiche and bricolage, thus pre-empting a highly postmodern articulation of subjectivity that moves beyond forms of subjugation to instances of agentic becoming that resists all-encompassing narratives of meaning and identity.

In the 1970s a number of artists started pushing the boundaries of collage and art practices of fragmentation by pointing to issues that emerged with the advent of digital technologies. Etgar (2017) explains that these matters included homage practices, copyright breaches and forms of quotation, all problems that were becoming increasingly ambivalent and which prompted artists to question the "limits of collage by channelling its legacy as a mode of engagement with found images" (p. 14). Among these artists were American photographers 
Cindy Sherman and Richard Prince, who explored practices of fragmentation and appropriation in different forms.

In Sherman's early work Untitled film stills (1977-83), her imagery playfully refers to Hollywood's stereotypical images of women, while at the same time ridiculing their poses by adopting awkward and stiff postures (Silverman, 1996). Crimp (2017) argues that Sherman's staged photographs appear as referential fragments or quotations from film narratives. For Sandbye (2018), Sherman's work suggests a cinematic artifice and shows that the screen functions as a cultural mirror that encourages certain conventions and normative forms of self-identity construction, while it also prompts the viewer to reflect on the cultural codes that are available through current visual culture. In the case of Prince, his work from the 1970 s was based on re-appropriating advertising photographs by re-photographing a fragment of them and excluding any referential material from the original image. He conceives his technique as stealing existing images in order to 'manage' them, instead of quoting them (Prince, 2017). Photography plays a key role in the work of Sherman and Prince, providing a platform that Banash (2013) considers as the base for visual practices ingrained in the re-appropriation of disposable and commodified culture. While Sherman's and Prince's practices are not literally based on collage methods of cut and paste, both work with images from visual culture which they reference or re-appropriate by taking them out of context and reintroducing them with new meanings. Such operations reflect the fundamental principles of fragmentation and appropriation, approaches that have become pervasive through contemporary digital technologies. The video montage in this fold entitled The Oasis of the Region (2019) by the Chilean artist Nicholas Rupcich is an eloquent example of this phenomenon.

Rupcich's work emerged in response to the socio-political outbreak in Chile on October 2019. After more than 30 years of democracy, the country still functions under a ubiquitous neoliberal system imposed in 1973 during a dictatorship that privatized most public services and natural resources, and which set the basis for one of the most unequal countries among the oECD. While secondary students initiated the social uprising, it promptly engaged the whole society through massive and continuous protests over economic inequality that were then retaliated by its president through a state of emergency and severe repressive measures. Deploying military forces resulted in confrontations against radical groups and pacifist demonstrators. This context led to an upsurge of human rights abuses from the part of the police and the military, an issue that escalated since the social movement spawned and continues to this day. Rupcich's video ironically alludes to a recent presidential statement-widely published in international news reports-that depicts Chile as an "oasis" in Latin America (Dorfman, 2020, para. 9). In the video, the 
artist articulates the president's declaration in relation to the violent and dystopic images that currently circulate in social media. Rupcich explains that this idealistic vision of the country as a leader of Latin America has been spread throughout the world and aligns with the logic of the market. Here, Chile appears as a commodity, wherein the nation appropriates multiple aesthetic codes and aspirations from the United States. For Rupcich, this distorted view turns certain suburban areas of Chile into a 'reality show', a prefabrication of reality underpinned by imported advertising conventions that lack connection with any aspects of the country's identity. He contends that Chile's identity has been eclipsed by an emphasis on exchange values, which has led the country to profound inequality. In this context, Rupcich's work re-appropriates a video commercial devised by the government to entice tourism from overseas through Chile's natural attractions. He juxtaposes this aesthetically stylised image of the country against a sequence of anonymous footage found in social media and which captures shocking and violent confrontations between protesters, the police, and military forces (See Figure 3).

In Rupcich's video, the juxtaposition of the glossy and utopian pamphlet of Chile with a violent and fractured narrative reveals the contradictions of neoliberal capitalism, a discourse that divides and conquers by turning communities into autonomous units. Here, fragmentation serves as a powerful tool of critique that enabled the artist to convey contradictory discourses: the extremely fragmented will of capitalist societies and the power of collectivism that challenges individualism that provides the 'glue' for a shared vision and

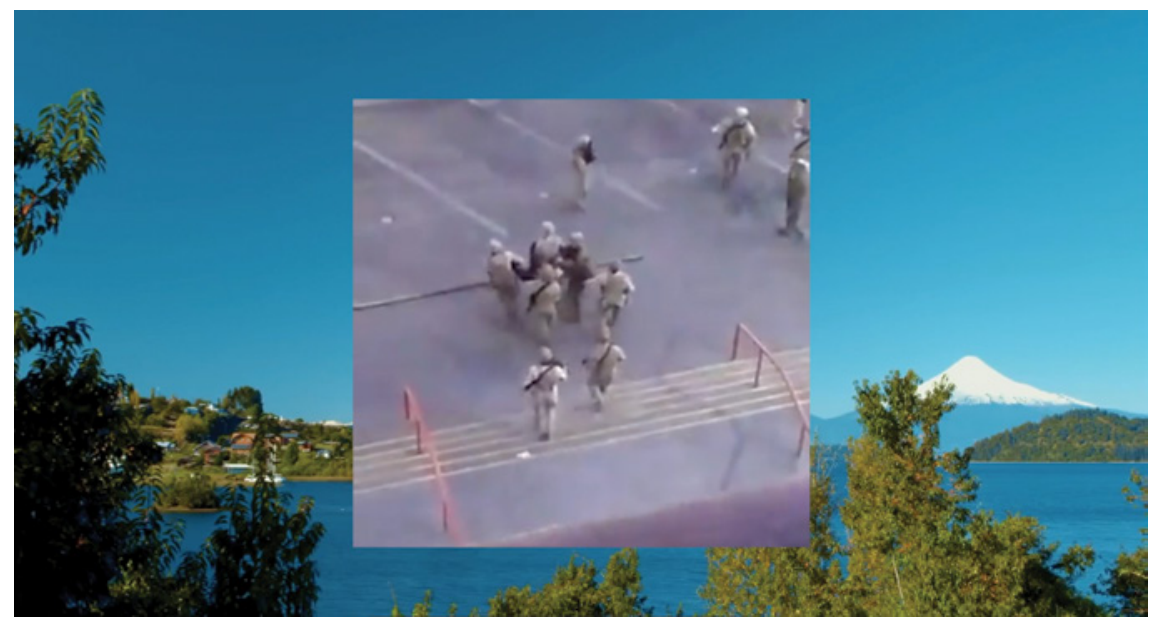

FIGURE 3 Still frame of Rupcich's video The Oasis of the Region [remix of Chile.travel video and anonymous footages]. (See full video here.) 
collectivist approach to resistance alongside a desire for social change. Some of the effects of posting this fragmentary video online, however, were unexpected. As Rupcich explains, while most responses praised his work as a denouncement, a minority expressed discontent to what was seen as 'bad publicity' for Chile, a derisory reaction when the video is compared with the myriad of violent images of the country that have been recently spread online. For Rupcich, his video cannot sabotage Chile's purported image. This concern of the appearance of the atrocities captured in the violent images only reveals how neoliberal discourses value profit up to the point of dissociating individuals from their humanity in a globalised, but fragmented world. New technologies have increased this sense of fragmentation, where the user-centric focus of social media spawns individuals' celebratory discourses, and structures the way in which the world is experienced and articulated through that subjectivities that are contradictory, multiple, fragmented and always in-flux.

Fold 4: Liquid and Fragmented Subjectivities

As visual technologies continue to shape our daily life, attempts to capture subjectivities give way to forms of thinking about the self as liquid and fragmented. jagodzinski (2010) asserts that the connection between the self and visual technologies springs from the increasing aestheticization of daily life in a capitalist-consumer culture, a context in which the screen serves as a platform for consuming and performing the continuous deconstruction of the adaptable-self. Under this logic individuals are prompted to become a liquid self', who is no longer defined by their ethnicity, gender, class or sexual orientation, but who is able to continually morph according to what they consume (jagodzinski, 2008; 2010). The individual who is continually prompted to update itself aligns with Norris's (1990) appraisal of postmodern fragmentation, a context in which the subject appears decentred and fractured by the crisis of grand-narratives and compelled to adopt and adapt fragments of themselves. While Jameson (1984) considers fragmentation as a loss of political power caused by late capitalism, McRobbie (2005) argues that this can lead to new forms of struggle (p. 71):

[The question is] how might the continual process of putting oneself together be transformed to produce the empowerment of subordinate groups and social categories. This might mean living with fragmentation, with the reality of inventing the self rather than endlessly searching for the self. 
In the context of a highly visual world, fragmentation is captured through postmodern visual culture (Garcia Lazo, 2018). Selfies, the seemingly 'spontaneous' self-portraits, reflect the conditions of fragmented subjectivities through images. While such imageries are commonly seen as narcissistic, superficial and a symptom of consumerist desire, Murray (2015) considers them to be a social phenomenon that is capable of generating political involvement. Despite selfies' potential, he recognizes that this form of visual culture can be contradictory, as these can adopt paradoxical discourses. Genz (2009) concurs with Murray's appraisal and claims that these self-imageries escape easy labelling as they intersect multiple discourses and trouble univocal meanings. McRobbie (2005) explains that fragmented subjectivities appear to reflect eclectic identities, which have borrowed second-hand pieces from heterogenous sources, an aspect that "is expressed in post-modern cultural forms, a kind of superficial pick-and-mix of styles" (p. 27). Fragmentation, however, oscillates between pleasure and political empowerment since it is a way of challenging unifying discourses of selfhood. The poem and video collage of workshop participant O'Connor captures the complexity and pleasures that underlie the idea of continuously appropriating and assembling cultural artefacts into the narratives of the fragmented self:

\author{
I am a human collage, \\ collecting and wearing all the colours, \\ patterns, textiles and talismans, \\ all at once. \\ When added together this visual cacophony gives me comfort \\ and tells stories about who I am \\ and who I hold dear.
}

O'Connor's image and poem appears to be a metaphor of the way in which individuals act as hoarders who appropriate fragments of narratives and assemble them in a hybrid fashion. An assemblage of visual culture and fetish is evident in this still frame that shows O'Connor wearing a top with the iconic Steve Zissou movie character design and a Pasifika shell necklace while posing with her recycled magazines collage, which resembles Māori striped patterns (see Figure 4). Here, fragments of narratives and commodities take the form of a rather familiar cadavre exquis. This familiarity could be triggered by the fact that images with the form of cultural assemblages have proliferated through digital technologies that facilitate the merging of multiple "media that collectively bespeak the complexity of the ... increasingly fragmented human condition" (Helfand, 2001, p. 55). Heartney (2001) posits that the work of Cindy 


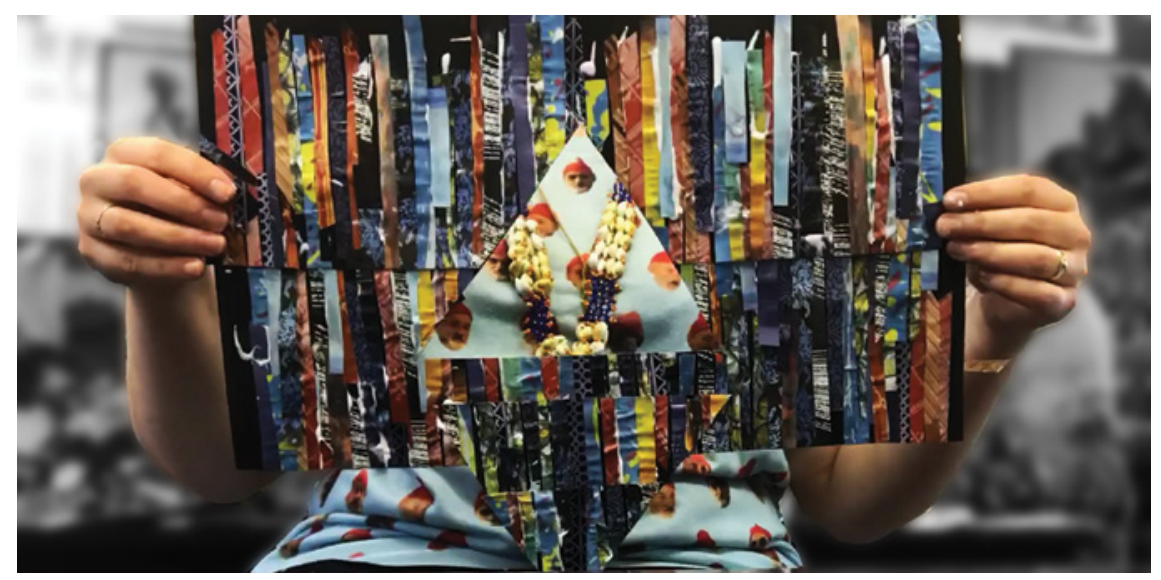

FIGURE 4 Still frame of O'Connor's video while making her collage. (See full video here.)

Sherman, whose multifaceted photographs employ herself as the model, embodies the same dilemma. Her photographs capture how the forces of late capitalism and fragmentation drive the construction of subjectivity beyond binary and static discourses, but also towards the collection of residual appropriations. Sherman's latest imagery includes her exploration of Instagram, where she began to share multiple images of herself distorted and deformed through default applications. Her pictures reveal a woman of a thousand masks as she uploads experiences from her daily life. For Farago (2017), Sherman's Instagram photographs make evident that the roles and facades engaged in social media are not imposed, but embraced and performed (para. 13):

We perform them ourselves, and the mark of their perniciousness is that we don't even notice ... Sherman has reaffirmed online that we are almost never the selves in our selfies - and that the most hazardous disguises are the forced smiles we now whiten with our index fingers.

Indeed, Hess (2015) states that current visual self-narratives are distinguished by the use of available filters through which certain aspects are transformed until a staged version of the self is attained. While digital devices mediate individuals' relation to the world through a screen, produced images are most likely re-configurated before being posted in social media to satisfy "the conflicted need for fleeting connection with others" (p. 1631). Garcia Lazo's fake Instagram graduation post featuring Locke parodies this urge for registering personal experiences, creating and posting second hand imagery to be under the spotlight of visibility (see Figure 5). 


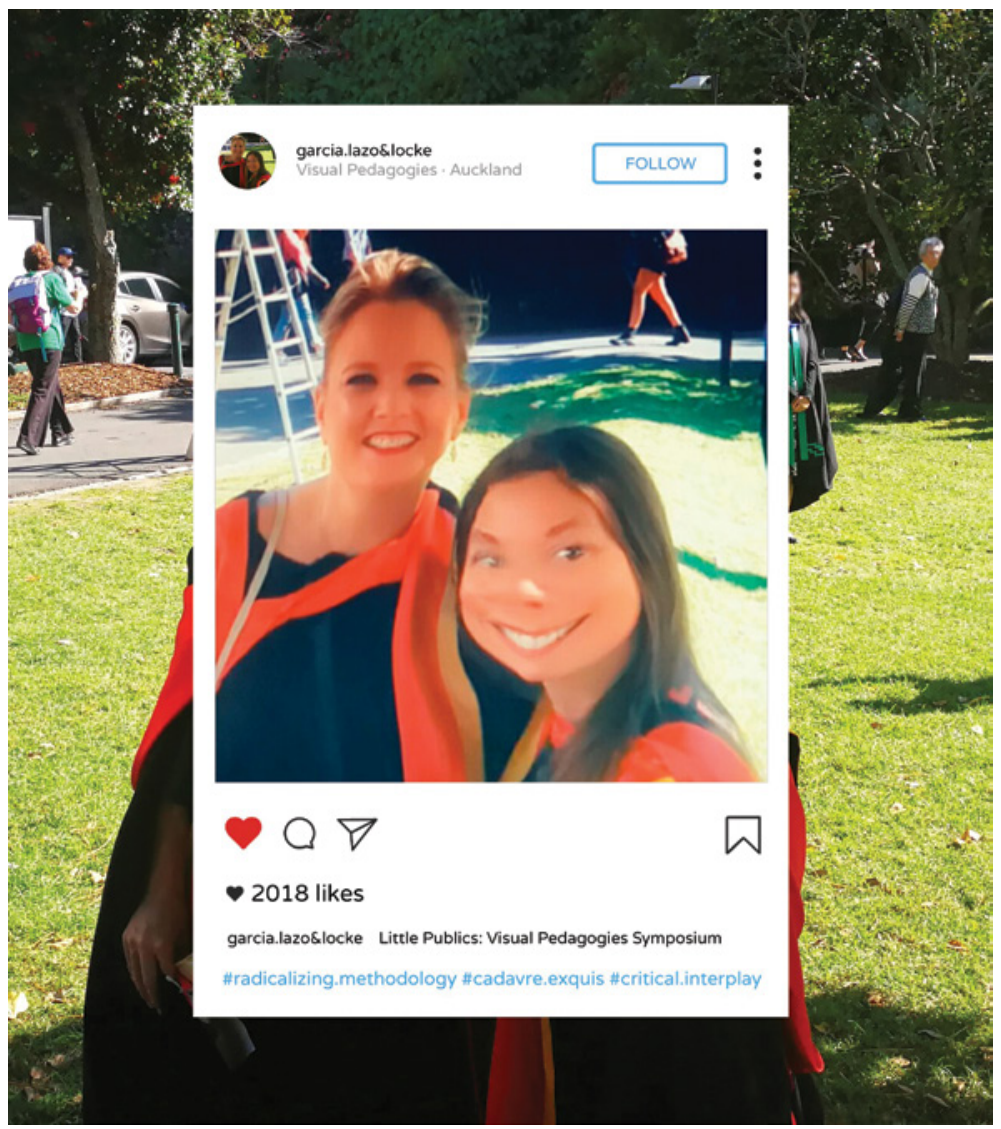

FIGURE 5 \#ego-propping. Note: The image Ego-propping includes an Instagram template designed by Freepik.com

The false Instagram image mocks the idea of ego propping, a popular practice through which individuals seek to elevate themselves in relation to a group by posting certain imagery. Lambert (2013) explains that this operation is frequently based on an "occasion of pride" that deserves to be promptly shared and celebrated, and which "is conditioned by a reciprocal social capital process” (p. 162). Inspired by Sherman's staged social media images, Garcia Lazo's fake post reflects the performative character of digital self-imagery, in which the drives for documenting personal events and entertaining an audience appear conflated and fragmentary. Indeed, new technologies offer means of articulating subjectivities in ways that enact the principle of collage through practices of fragmentation that have turned the once disruptive juxtaposition of images into an immaterial, ubiquitous and familiar daily experience. 
This collective writing experiment has attempted an enactment of collage that has used temporal junctures of time and place, and material affects in the form of different media, forms and styles of writing, and multiple authorial voices. Just as the surrealists would have taken delight in the unfolding of the cadavres exquis as an act of meaning-making and psychological disclosure, this 'final' fold explores the pedagogical potential of collage in relation to the effects of late capitalism. While fragmentation has been presented in Fold 1 as predominantly a symptom of our late capitalist era, the ensuing 'folds' of the article have expressed the subjective multiplicity inherent in the methodology of collage as an act of resistance and agentic subjectification in ways that highlight the potential connections between disparate fragments and folds. The pedagogical potentiality of collage lies in the way its methodology reflects the construction of selfhood as a site of tension where divergent pieces assemble. While the operations of cut and paste echo the role of the consumer, collage allows one to adopt a conscious and critical position towards the consuming self as driven by desires which entail complicity in forms of capitalist oppression (Poletti, 2008, p. 161). It is here that a return to Deleuze's and Guattari's account of desire is useful as a pedagogical construct. Rather than merely considering ideology as the key of capitalism, Deleuze and Guattari (2004) suggest that "the organization of power is the unity of desire and the economic infrastructure" (p. 264). Here, we concur with Poletti's (2008) consideration of collage as a critical platform that enables us to reflect on the fluid and contradictory operations implicated in the construction of the self, where desires can simultaneously point to consume the seductive narratives of the market and to an ethical commitment to social justice. In the context of education, we consider that engaging with the methodology of collage enables us to contextualize and reveal the forces that are at play in diverse forms of self-narratives and representations of society.

Each fold of this article is to be engaged with as a challenge to this idea, alongside a conception of education as consisting of multiple and fluid forces that have implications for young people who take part in shifting forms of identitymaking ingrained in the culture of the adaptable subject and the desiring self. It is this final point that we pause with, to consider the political dimensions of fragmentation in ways that provide young people interesting and productive spaces to consider themselves differently. The collages embedded in this article provide evidence of the deconstructive capacity of this methodology for uncovering the complexities involved in the fabrication of social or personal identity in the context of late capitalism while resisting binary accounts of 
selfhood. This dialectical capacity of collage lies in its transdisciplinary potential. As a transdisciplinary practice, collage is not limited to specific genres, mediums or disciplines, but enables the combination of these (Scotti \& Chilton, 2015). Collage embraces creativity and difference, and as such its pedagogical applicability has the potential of providing a critical framework for exploring multiple and co-existent realities and identities as well as revealing their connections with wider society. Problematizing fragmentation, and engaging in the pedagogical process of folding and unfolding through collage, in this light can be seen as productive dimensions that resist ideas of selfhood as universal and all-encompassing. This article is a trans-disciplinary intervention that performs this resistance.

\section{References}

Banash, D. (2013). Collage culture: Readymades, meaning, and the age of consumption. New York, NY: Rodopi.

Besana, T., Katsiaficas, D., \& Brittian Loyd, A. (2019). Asian American media representation: A film analysis and implications for identity development. Research in Human Development, 16(3-4), 201-225. doi:10.1080/15427609.2020.1711680.

Cran, R. (2014). Collage in twentieth-century art, literature, and culture: Joseph Cornell, William Burroughs, Frank O'Hara, and Bob Dylan. Farnham, England: Ashgate.

Crimp, D. (2017). Pictures. In Y. Etgar (Ed.), The ends of collage (pp. 197-210). London, England: Luxemburg \& Dayan.

Deleuze, G. (1992). The fold: Leibniz and the baroque. Minneapolis, MN: University of Minnesota Press.

Deleuze, G., \& Guattari, F. (1987). A thousand plateaus: Capitalism and schizophrenia. London, England: Athlone Press.

Deleuze, G., \& Guattari, F. (2004). Desert islands and other texts: 1953-1974. New York, NY: Semiotext(e).

Dorfman, A. (2020, January 24). The challenge for Chile and the world: Can the selfserving political elites address the demands of radicalized and disaffected citizens? The New York Times. Retrieved from: https://www.nytimes.com/2020/01/24/ opinion/chile-protests.html.

Drucker, J. (2005). Sweet dreams: Contemporary art and complicity. Chicago, IL: University of Chicago Press.

Drucker, J. (2009). Making space: Image events in an extreme state. In F. Franscina (Ed.), Modern art culture: A reader (pp. 25-45). New York, NY: Routledge.

Dyer, R. (2007). Pastiche. New York, NY: Routledge. 
Ellison, S. (2019). Against fragmentation: Critical education scholarship in a time of crisis. Educational Studies, 55(3), 271-294. doi:10.1080/00131946.2019.1605366.

Etgar, Y. (2017). The ends of collage. London, England: Luxemburg \& Dayan.

Farago, J. (2017, August 6). Cindy Sherman takes selfies (as only she could) on Instagram. The New York Times. Retrieved from: https://www.nytimes.com/2017/08/06/ arts/design/cindy-sherman-instagram.html.

Garcia Lazo, V. (2018). (Re) Imagining critical thinking through the visual (Doctoral thesis). The University of Auckland, Auckland, New Zealand.

Grushka, K. (2005). Creative engagements with visual culture, communicative knowing, citizenship and contemporary visual arts education. In N. Jeanneret \& G. Gardiner (Eds.), Backing our creativity: Research, policy, practice (pp. 61-71). Sydney, Australia: The Australian Council for the Arts.

Genz, S. (2009). Postfemininities in popular culture. Basingstoke, England: Palgrave Macmillan.

Heartney, E. (2001). Postmodernism. Cambridge, England: Cambridge University Press. Helfand, J. (2001). Screen: Essays on graphic design, new media and visual culture. New York, NY: Princeton Architectural Press.

Hess, A. (2015). The selfie assemblage. International Journal of Communication 9(2015), 1629-1646. Retrieved from: https://ijoc.org/index.php/ijoc/article/view File/3147/1389.

Heywood, I., \& Sandywell, B. (2012). Critical approaches to the study of visual culture. In I. Heywood, B. Sandywell, M. Gardiner, C. M. Soussloff, \& G. Nadarajan (Eds.), The handbook of visual culture (pp. 1-58). London, England: Berg.

jagodzinski, j. (2008) Postmetaphysical vision: Art education's challenge in an age of globalized aesthetics (a mondofesto). Studies in Art Education, 49(2), 147-16o. doi: 10.1080/00393541.2008.11518732.

jagodzinski, j. (2010). Visual art and education in an era of designer capitalism: Deconstructing the oral eye. New York, NY: Palgrave Macmillan.

Jameson, F. (1984). Postmodernism, or the cultural logic of capital. New Left Review, 146 (July-August), 53-92.

Jameson, F. (2002). Postmodernism and consumer society. In H. Foster (Ed.), The antiaesthetic: Essays on postmodern culture (pp. 127-144). New York, NY: The New York Press.

Lambert, A. (2013). Intimacy and friendship on Facebook. New York, NY: Palgrave Macmillan.

Lee, S. (2009). Unraveling the "model minority" stereotype: Listening to Asian American youth. New York, NY: Teachers College Press.

Lippard, L. R. (1995). The pink glass swan: Selected feminist essays on art. New York, NY: The New Press. 
Lyotard, J. F. (1984). The postmodern condition: A report on knowledge. Manchester, England: Manchester University Press.

Lyotard, J. F. (1988). The differend: Phrases in dispute. Manchester, England: Manchester University Press.

Mok, T. A. (1998) Getting the message: Media image and stereotypes and their effect on Asian Americans. Cultural Diversity and Mental Health, (3), 185-202.

McRobbie, A. (2007). Postmodernism and popular culture. London, England: Routledge.

Murray, D. C. (2015). Notes to self: The visual culture of selfies in the age of social media. Consumption Markets \& Culture, 18(6), 490-516. doi:10.1080/10253866.2015.1052967.

Norris, C. (1990). Lost in the funhouse: Baudrillard and the politics of postmodernism. In R. Boyne \& A. Rattansi (Eds.) Postmodernism and Society (pp. 119-34). London, England: Macmillan.

Prince, R. (2017). Practicing without a license 1977. In Y. Etgar (Ed.), The ends of collage (p. 211). London, England: Luxemburg \& Dayan.

Raaberg, G. (1998). Beyond Fragmentation: Collage as Feminist Strategy in the Arts. Mosaic, 31(3), 153-171.

Sandbye, M. (2018). Selfies and purikura as affective, aesthetic labor. In J. Eckel, J. Ruchatz \& S. Wirth (Eds.), Exploring the selfie: Historical, theoretical, and analytical approaches to digital self-photography (pp. 305-326). Copenhagen, Denmark: Palgrave Macmillan.

Todd, S. (2003). Learning from the other: Levinas, psychoanalysis, and ethical possibilities in education. Albany, NY: State University of New York Press.

Usher, R., \& Edwards, R. (1994). Postmodernism and education. London, England: Routledge. 